\title{
Safety and Utility of Kidney Biopsy in Elderly Patients: \\ A Single-Center Cohort Study
}

\author{
Tomo Suzuki, Kayori Tsuruoka, Daisuke Ichikawa, \\ Sayuri Shirai, and Yugo Shibagaki
}

(Received for Publication: August 24, 2015)

\begin{abstract}
BACKGROUND The number of elderly patients with kidney disease is increasing rapidly, and we often encounter situations in which we need to weigh the benefits and risks of kidney biopsy (KBx). The decision is often difficult because reports addressing the safety and utility of KBx in the elderly are scarce.

METHODS This observational study included 548 consecutive adult patients who underwent native KBx. We divided the patients into an E group, elderly patients 65 years or older, and an NE group, the remaining nonelderly patients. Baseline characteristics and complications of $\mathrm{KBx}$ were compared between the two groups. We also investigated the proportions of patients in whom steroid and/or immunosuppressive treatment was started after KBx.

RESULTS There were 112 patients in the E group and 436 in the NE group. The baseline values differed significantly between the groups for age $(71.5 \pm 4.7$ vs. $39.6 \pm 13.9$ years $)$, estimated glomerular filtration rate (eGFR) $\left(41.4 \pm 27.1\right.$ vs. $\left.72.0 \pm 33.7 \mathrm{ml} / \mathrm{min} / 1.73 \mathrm{~m}^{2}\right)$, proportion of patients with diabetes $(25.0 \%$ vs. $4.8 \%)$, and proportion of those who underwent surgical $\mathrm{KBx}(11.6 \%$ vs $3.0 \%)$, There was no significant difference in terms of sex.

The E group experienced slightly more major complications (4.0\% vs. $1.2 \%, \mathrm{p}=0.05)$ but fewer minor complications $(2.0 \%$ vs. $6.0 \%$, p=0.10) with percutaneous $\mathrm{KBx}$ than the NE group did, although neither major nor minor complications occurred in patients who underwent surgical KBx. Final diagnoses after KBx, such as IgA nephropathy, IgA vasculitis, and ANCA-associated glomerulonephritis, were associated with various clinical diagnoses, indicating that the final diagnoses could not have been obtained without KBx. Treatment with steroid and/or immunosuppressant was required to a high degree in patients with ANCA-associated glomerulonephritis and minimal change disease after histologic evaluation by KBx.
\end{abstract}

CONCLUSIONS The risk of KBx in the elderly patients was significantly higher than that in the non-elderly, and some diagnoses could not have been obtained without KBx. Thus, as long as nephrologists perform KBx cautiously according to strict indications, KBx can be a safe and useful option in the management of kidney disease in the elderly.

\section{Key words}

kidney biopsy, elderly patients, complication

\section{Introduction}

The average life expectancy of Japanese is reported to be more than 80 years, and it continues to rise. A recent study of the Japanese general population showed that the prevalence of chronic kidney disease $(\mathrm{CKD})$ is also increasing, especially in the elderly population, and the prognosis for elderly pa-

Division of Nephrology and Hypertension, Department of Internal Medicine, St. Marianna University School of Medicine, Kanagawa, Japan 
tients with CKD in the presence of proteinuria is poor $^{122)}$. Furthermore, morbidity is higher in the elderly population for both acute kidney injury (AKI) and rapid progressive glomerulonephritis (RPGN), especially in those more than 80 years old ${ }^{344}$. Therefore, it is important to treat CKD, even in the elderly, by making a definitive diagnosis.

However, we tend not to perform kidney biopsy $(\mathrm{KBx})$ in the elderly, probably because of the increased risk for complications despite the fact that we use ultrasound-guided methods and that open surgical biopsy may be selected for those who are at high risk for complications from $\mathrm{KBx}$, such as those with a single kidney, thrombocytopenia, or amyloidosis ${ }^{5 / 6)}$. Although some reports showed that KBx for elderly patients carried a greater risk for complications when there was co-existent $\mathrm{CKD}^{7)}$, Yang et al reported recently that the elderly did not have major complications after $\mathrm{KBx}^{8}$. Thus, the safety of $\mathrm{KBx}$ is still controversial.

The other reason for not performing $\mathrm{KBx}$ in the elderly is that we are not sure whether KBx in elderly patients can provide useful diagnostic information that outweighs the risk of KBx. Likewise, it is uncertain whether the results of $\mathrm{KBx}$ in the elderly will change disease management and positively affect the prognosis.

The purpose of this study was to elucidate whether $\mathrm{KBx}$ is safe and useful in the elderly by comparing them with a non-elderly population.

\section{Materials and methods}

The subjects were 548 consecutive patients who underwent KBx between 2004 and 2011 in the nephrology ward at St. Marianna University Hospital, which is a tertiary care university-affiliated hospital. The study was approved by the Institutional Committee on Human Research of St. Marianna University School of Medicine (approval number 3028). We defined elderly patients (E group) as those $\geq 65$ years old; the remainder were classified as the non-elderly patients (NE group) based on World Health Organization definitions.

The clinical diagnoses of the kidney diseases before $\mathrm{KBx}$ was performed were classified into six categories: RPGN, nephrotic syndrome, asymptomatic hematuria and/or proteinuria, non-nephrotic range proteinuria, AKI without hematuria and proteinuria, and isolated hematuria. We excluded patients with an uncertain histologic diagnosis and those who underwent a second $\mathrm{KBx}$ or allograft biopsy.
Percutaneous KBx was performed by two or more experienced nephrologists using a 16-gauge needle under real-time ultrasonographic guidance. Surgical KBx was selected if the attending nephrologist deemed it safer, and it was performed under general anesthesia by urologists. In addition, patients who received steroid and/or immunosuppressive therapy prior to the biopsy were excluded.

Major complications were defined as bleeding or arteriovenous fistula formation that required intervention such as transfusion of blood products or invasive radiologic or surgical procedures. Minor complications included perinephric hematoma that was resolved easily after crystalloid fluid infusion and required no other intervention, gross hematuria, and hypotension.

We determined the proportions of patients who received steroid and/or immunosuppressive therapy after $\mathrm{KBx}$ as classified by final diagnoses (only for diagnoses applied to more than 5 patients).

All values are expressed as mean \pm standard error (SE). Patient groups were compared by Student $t$ test and Pearson's chi-square test for baseline characteristics, indications for $\mathrm{KBx}$, and complications of KBx. Statistical significance was set at $p<0.05$. Statistical analyses were performed with JMP 11.0.0 (SAS Institute Inc.).

\section{Results}

\section{Baseline characteristics}

$\mathrm{KBx}$ was performed during the study period in 548 patients, 112 of whom belonged to the E group (Table 1). The baseline values differed significantly between the groups for age $(71.5 \pm 4.7$ vs. 39.6 \pm 13.9 years $)$, eGFR $(41.4 \pm 27.1$ vs. $72.0 \pm 33.7$ $\mathrm{ml} / \mathrm{min} / 1.73 \mathrm{~m}^{2}$ ), the proportion of patients with diabetes $(25.0 \%$ vs. $4.8 \%)$, and the proportion of those who underwent surgical KBx (11.6\% vs 3.0\%). There was no significant difference in sex.

\section{Complications of $\mathrm{KBx}$}

The complications of KBx are shown in Table 2. Overall, complications resulting from percutaneous biopsy occurred infrequently in both the E group $(6.1 \%)$ and NE group (7.3\%), and no complications occurred as a result of surgical KBx. Major complications were uncommon and tended to occur slightly more frequently in the E group (4.0\% vs. $1.2 \%, \mathrm{p}=$ $0.05)$. The final diagnoses in the patients with a major complication are shown in Table 3. Amyloidosis, which confers a bleeding risk ${ }^{6}$, was not involved. 
Table 1. Baseline Characteristics of Study Population

\begin{tabular}{|c|c|c|c|}
\hline Characteristics & $\begin{array}{c}\text { Elderly } \\
(\mathrm{n}=112)\end{array}$ & $\begin{array}{c}\text { Non-elderly } \\
(\mathrm{n}=436)\end{array}$ & P value \\
\hline $\begin{array}{c}\text { Gender } \\
\text { (male / female) }\end{array}$ & $52 / 60$ & $213 / 223$ & 0.65 \\
\hline Age - year & $71.5 \pm 4.7$ & $39.6 \pm 13.9$ & $<0.01$ \\
\hline eGFR (ml/min/1.73 $\left.\mathrm{m}^{2}\right)$ & $41.4 \pm 27.1$ & $72.0 \pm 33.7$ & $<0.01$ \\
\hline Diabetes (\%) & 25.0 & 4.8 & $<0.01$ \\
\hline $\begin{array}{c}\text { Biopsy (n.\%) } \\
(\text { Percutaneous / Surgical) }\end{array}$ & $\begin{array}{c}99 / 13 \\
(88.4 / 11.6)\end{array}$ & $\begin{array}{c}423 / 13 \\
(97.0 / 3.0)\end{array}$ & $<0.01$ \\
\hline
\end{tabular}

Table 2. Complication of Kidney Biopsy Comparing the Elderly and Non-elderly

\begin{tabular}{|c|c|c|c|}
\hline Complication & $\begin{array}{c}\text { Elderly } \\
(\mathrm{n}=112)\end{array}$ & $\begin{array}{c}\text { non-elderly } \\
(\mathrm{n}=436)\end{array}$ & P value \\
\hline Percutaneous biopsy & 99 & 423 & \\
Total complication no. (\%) & $6(6.1)$ & $31(7.3)$ & 0.65 \\
Major complication no. (\%) & $4(4.0)$ & $5(1.2)$ & 0.05 \\
Invasive radiologic procedure & 3 & 3 & \\
Nephrectomy & 0 & 0 & \\
Transfusion & 1 & $26(6.1)$ & 0.10 \\
Minor complication no. (\%) & $2(2.0)$ & 13 & \\
Surgical biopsy & 13 & 0 & \\
Major complication no. (\%) & 0 & 0 & \\
Minor complication no. (\%) & 0 & & \\
\hline
\end{tabular}

Table 3. Final Diagnosis with Major Complications Comparing the Elderly and Non-elderly

\begin{tabular}{|c|c|c|}
\hline $\begin{array}{c}\text { Final diagnosis of major } \\
\text { Complications }\end{array}$ & $\begin{array}{c}\text { Elderly } \\
(\mathrm{n}=4)\end{array}$ & $\begin{array}{c}\text { non-elderly } \\
(\mathrm{n}=5)\end{array}$ \\
\hline Invasive radiologic procedure & $\begin{array}{c}\text { ANCA associated } \\
\text { glomerulonephritis:1case } \\
\text { Focal segmental } \\
\text { glomerulosclerosis:1 } \\
\text { Post infectious } \\
\text { glomerulonephritis:1case }\end{array}$ & $\begin{array}{c}\text { Minimal change disease:1case } \\
\text { Obesity related } \\
\text { glomerulopathy:1case } \\
\text { IgA nephropathy:1case }\end{array}$ \\
\hline Transfusion & Lupus nephritis:1case & $\begin{array}{c}\text { Membranoproliferative } \\
\text { glomerulonephritis secondary } \\
\text { to HCV:1case }\end{array}$ \\
\hline
\end{tabular}

\section{Clinical and final diagnoses of kidney diseases}

The clinical diagnoses of the study patients before $\mathrm{KBx}$ are shown in Table 4. In the $\mathrm{E}$ group, RPGN was the most frequent clinical diagnosis, whereas asymptomatic hematuria and/or proteinuria was the leading clinical diagnosis in the NE group.
There were no significant differences in the frequencies of the other clinical diagnoses between the two groups. The proportions of the various kidney diseases were the same as previously reported in Japan ${ }^{9)}$.

In the E group, 8 patients were excluded because of uncertainty in the diagnoses, leaving 104 
Table 4. Indications (clinical diagnoses) of Kidney Biopsy Comparing the Elderly with Non-elderly

\begin{tabular}{|c|c|c|c|}
\hline indication n (\%) & $\begin{array}{c}\text { Elderly } \\
(\mathrm{n}=112)\end{array}$ & $\begin{array}{c}\text { Non-elderly } \\
(\mathrm{n}=436)\end{array}$ & P value \\
\hline Rapid progressive glomerulonephritis & $34(30.3)$ & $18(4.1)$ & $<0.01$ \\
\hline Nephrotic syndrome & $33(29.5)$ & $97(22.3)$ & 0.11 \\
\hline $\begin{array}{c}\text { Asymptomatic hematuria and } \\
\text { proteinuria }\end{array}$ & $33(29.5)$ & $240(55.1)$ & $<0.01$ \\
\hline $\begin{array}{c}\text { Non-nephrotic range proteinuria } \\
\text { Acute kidney injury without hematuria } \\
\text { and proteinuria }\end{array}$ & $8(7.1)$ & $46(10.6)$ & 0.28 \\
\hline $\begin{array}{c}\text { Isolated hematuria } \\
\text { (3.6) }\end{array}$ & $29(6.7)$ & 0.22 \\
\hline
\end{tabular}

Table 5. Final Diagnoses by Kidney Biopsy in the Elderly

\begin{tabular}{|c|c|c|c|}
\hline Diagnosis & $\mathrm{n}(\%)$ & Diagnosis & $\mathrm{n}(\%)$ \\
\hline ANCA associated glomerulonephritis & $25(24.0)$ & $\begin{array}{l}\text { Membranous glomerulonephritis } \\
\text { with interstitial nephritis secondary to } \\
\text { Sjögren's syndrome-associated } \\
\text { cryoglobulinemia }\end{array}$ & $2(1.9)$ \\
\hline Membranous glomerulonephritis & $13(12.5)$ & Anti GBM disease & $1(1.0)$ \\
\hline IgA nephropathy & $11(10.6)$ & $\begin{array}{l}\text { Focal segmental glomerulosclerosis } \\
\text { secondary to unkwown }\end{array}$ & $1(1.0)$ \\
\hline IgA vasculitis & $11(10.6)$ & Immunotactoid glomerulopathy & $1(1.0)$ \\
\hline Minimal change disease & $6(5.8)$ & Idiopathic crescent glomerulonephritis & $1(1.0)$ \\
\hline Post infectious glomerulonephritis & $4(3.8)$ & Lipoprotein glomerulopathy & $1(1.0)$ \\
\hline AL amyloidosis & $3(2.9)$ & Interstitial nephritis due to salcoidosis & $1(1.0)$ \\
\hline Diabetic nephropath & $3(2.9)$ & $\begin{array}{l}\text { Membranoproliferative } \\
\text { glomerulonephritis secondary to HBV }\end{array}$ & $1(1.0)$ \\
\hline Interstitial nephritis & $3(2.9)$ & $\begin{array}{l}\text { Membranous proliferative } \\
\text { glomerulonephritis secondary to } \\
\text { lymphoma }\end{array}$ & $1(1.0)$ \\
\hline Light chain deposition disease & $3(2.9)$ & Nephrosclerosis & $1(1.0)$ \\
\hline $\begin{array}{l}\text { Membranous glomerulonephritis } \\
\text { secondary to cancer }\end{array}$ & $3(2.9)$ & Thin basement membrane disease & $1(1.0)$ \\
\hline AA amyloidosis secondary to RA & $2(1.9)$ & Warfarin related nephropathy & $1(1.0)$ \\
\hline Focal segmental glomerulosclerosis & $2(1.9)$ & Total & $104(100)$ \\
\hline Lupus nephritis & $2(1.9)$ & & \\
\hline
\end{tabular}

elderly patients to be analyzed for biopsy-proven final diagnoses (Table 5). ANCA-associated glomerulonephritis was the most frequent, followed by membranous glomerulonephritis (MN), IgA nephropathy, IgA vasculitis, and minimal change disease (MCD). Dysproteinemia, including monoclonal gammopathy of renal significance, AL amyloidosis, and light chain deposition disease accounted for 5.8\% (6 of 104).

To investigate the associations of clinical diagnoses before $\mathrm{KBx}$ with final diagnoses, we stratified the final diagnoses in the elderly by clinical diagnoses, as shown in Table 6. Final diagnoses such as
ANCA-associated glomerulonephritis, IgA nephropathy/IgA vasculitis, and dysproteinemia were associated with various clinical diagnoses. In other words, every clinical diagnosis had various final diagnoses. This underscores the utility of $\mathrm{KBx}$ in providing the specific diagnosis.

\section{Clinical course in the elderly patients after $\mathbf{K B x}$ (Table 7)}

Finally, we investigated the proportions of patients who recieved steroid/immunosuppressant after KBx. After excluding 4 patients who received ste- 
Table 6. Final Diagnoses Stratified by Clinical Diagnoses in the Elderly

\begin{tabular}{|c|c|c|c|c|c|c|c|c|c|}
\hline $\begin{array}{l}\text { Rapid progressive } \\
\text { glomerulonephritis }\end{array}$ & $\mathrm{n}$ & Nephrotic syndrome & $\mathrm{n}$ & Asymptomatic hematuria and proteinuria & $\mathrm{n}$ & Non-nephrotic range proteinuria & $\mathrm{n}$ & $\begin{array}{c}\text { Acute kidney injury } \\
\text { without hematuria and } \\
\text { proteinuria }\end{array}$ & $\mathrm{n}$ \\
\hline $\begin{array}{c}\text { ANCA associated } \\
\text { glomerulonephritis }\end{array}$ & 18 & $\begin{array}{c}\text { Membranous } \\
\text { glomerulonephritis }\end{array}$ & 11 & ANCA associated glomerulonephritis & 5 & Light chain deposition disease & 2 & $\begin{array}{l}\text { ANCA associated } \\
\text { glomerulonephritis }\end{array}$ & 2 \\
\hline IgA nephropathy & 4 & Minimal change disease & 6 & IgA nephropathy & 5 & Diabetic nephropathy & 2 & $\begin{array}{l}\text { Interstitial nephritis due } \\
\text { to salcoidosis }\end{array}$ & 1 \\
\hline IgA vasculitis & 3 & $\begin{array}{c}\text { Membranous } \\
\text { glomerulonephritis } \\
\text { secondary to cancer }\end{array}$ & 3 & IgA vasculitis & 5 & AL amyloidosis & 1 & Total & 3 \\
\hline Interstitial nephritis & 3 & IgA vasculitis & 3 & AA amyloidosis secondary to RA & 2 & $\begin{array}{c}\begin{array}{c}\text { Focal segmental } \\
\text { glomerulosclerosis secondary to } \\
\text { unkwown etiology }\end{array} \\
\end{array}$ & 1 & & \\
\hline Nephrosclerosis & 1 & $\begin{array}{l}\text { Focal segmental } \\
\text { glomerulosclerosis }\end{array}$ & 2 & $\begin{array}{c}\text { Membranous glomerulonephritis } \\
\text { with interstitial nephritis secondary to } \\
\text { Sjögren`s syndrome-associated } \\
\text { cryoglobulinemia } \\
\end{array}$ & 2 & Lipoprotein glomerulopathy & 1 & & \\
\hline $\begin{array}{l}\text { Idiopathic crescent } \\
\text { glomerulonephritis }\end{array}$ & 1 & IgA nephropathy & 2 & Lupus nephritis & 2 & Total & 7 & & \\
\hline $\begin{array}{l}\text { Light chain deposition } \\
\text { disease }\end{array}$ & 1 & $\begin{array}{l}\text { Post infectious } \\
\text { glomerulonephritis }\end{array}$ & 2 & Membranous glomerulonephritis & 2 & & & & \\
\hline $\begin{array}{l}\text { Warfarin related } \\
\text { nephropathy }\end{array}$ & 1 & AL amyloidosis & 1 & Post infectious glomerulonephritis & 1 & & & & \\
\hline \multirow[t]{8}{*}{ Total } & 32 & Diabetic nephropathy & 1 & Anti GBM disease & 1 & & & & \\
\hline & & Total & 31 & Immunotactoid nephropathy & 1 & & & & \\
\hline & & & & Diabetic nephropathy & 1 & & & & \\
\hline & & & & $\begin{array}{c}\text { Membranoproliferative glomerulonephritis } \\
\text { secondary to HBV }\end{array}$ & 1 & & & & \\
\hline & & & & $\begin{array}{c}\text { Membranoproliferative glomerulonephritis } \\
\text { secondary to lymphoma }\end{array}$ & 1 & & & & \\
\hline & & & & Nephrosclerosis & 1 & & & & \\
\hline & & & & Thin basement membrane disease & 1 & & & & \\
\hline & & & & Total & 31 & & & & \\
\hline
\end{tabular}

Table 7. Proportions of Those Who Received Steroid/ immunosuppressive Therapy after Kidney Biopsy in the Elderly Stratified by Final Diagnoses

\begin{tabular}{|c|c|}
\hline Diagnosis & $\mathrm{n}(\%)$ \\
\hline ANCA associated glomerulonephritis & $22 / 24(91.7)$ \\
\hline Membranous glomerulonephritis & $3 / 12(25.0)$ \\
\hline IgA nephropathy & $5 / 11(45.5)$ \\
\hline IgA vasculitis & $6 / 11(54.5)$ \\
\hline Minimal change disease & $5 / 6(83.3)$ \\
\hline
\end{tabular}

roids or immunosuppressive therapy before $\mathrm{KBx}, 100$ of the 104 patients with a final diagnosis were analyzed. Table 7 shows these proportions only for final diagnoses applied to more than 5 patients. The proportions were very high for ANCA-associated glomerulonephritis $(91.7 \%)$ and $\operatorname{MCD}(83.3 \%)$ but intermediate for IgA vasculitis (54.5\%), IgA nephropathy
(45.5\%), and membranous glomerulonephritis $(25.0 \%)$.

\section{Discussion}

The significant findings from this study were two-fold: $\mathrm{KBx}$ in the elderly was safe if performed with cautious discretion, and $\mathrm{KBx}$ was useful in determining the definite diagnosis and in subsequent management.

Although, $\mathrm{KBx}$ in the elderly led to a slightly higher incidence of major complications, the absolute incidence was low, and the overall complication rate was comparable to that in the non-elderly. In fact, the absolute incidence of major complications in the elderly of $4.0 \%$ was lower than that reported by Korbet et al (the rate of major complications after KBx under real-time ultrasound guidance and with the use of a 14-gauge needle was $6.6 \%)^{10)}$. However, Yang et al reported that the elderly patients they studied did not experience major complications, and only $8.3 \%$ of their patients experienced minor complications ${ }^{8)}$. However, the message we would like to convey is not that KBx in the elderly is safe. As shown by the fact 
that surgical biopsy was selected more often in the elderly, we often considered KBx in the elderly to be risky, and we performed it according to strict indications (such as high-mortality disease, which was ANCA-associated glomerulonephritis, when considering aggressive treatment in spite of potential side effects) and with cautious discretion (for example, by decreasing the number of punctures if the kidney was small and the kidney cortex was thin), which led to our relatively low complication rate. Rather, our message here is that if $\mathrm{KBx}$ is expected to be very useful in the diagnosis and management of the patient's condition, we would strongly consider $\mathrm{KBx}$ in the elderly as well as in the non-elderly but with caution.

For surgical biopsy, our study showed that there were no complications perioperatively. However, the risk for postoperative medical complications associated with general anesthesia can be serious and increased in the elderly, especially in those with dementia $^{11)}$. Considering these risks, it may be advisable to prioritize the percutaneous approach in elderly patients, especially in those with dementia.

Next, we showed the utility of KBx in the elderly in terms of diagnosis and management. It is very intriguing to see in Table 6 that every clinical diagnosis had various final diagnoses following $\mathrm{KBx}$. Biopsy-confirmed ANCA-associated glomerulonephritis, IgA vasculitis/nephropathy, and dysproteinemia, especially, had various clinical presentations. These findings definitely indicate that we could not have made the final diagnosis of a disease potentially treatable with aggressive therapy without the results of $\mathrm{KBx}$.

It is also intriguing to see the proportions of patients who received steroid/immunosuppressive therapy after KBx (Table 7). As shown in Table 4, there were significant differences in the proportions of clinical diagnoses between the two age groups in terms of the indications for KBx. One of the reasons why RPGN and nephrotic syndrome accounted for large proportions in the indications for $\mathrm{KBx}$ in the elderly may be that we tend to perform $\mathrm{KBx}$ in the elderly only when we are considering aggressive treatment with potential side effects (such as steroid/immunosuppressive therapy). Thus, the elderly in our study may have undergone $\mathrm{KBx}$ as a final determining factor for the administration of aggressive therapy. In this regard, it is very interesting to see that the proportion of elderly patients receiving aggressive therapy was intermediate for membranous glomerulonephritis and IgA vasculitis/nephropathy, indicating that we reconsidered (modified) our management decision according to the results of KBx. In Japan, IgA nephropathy is one of the most frequent glomerular diseases. In the elderly, it presents clinically more frequently than RPGN, AKI, and nephrotic syndrome $^{3)}$, findings that are similar to those in our study. The prognosis for IgA nephropathy is poor, and over $70 \%$ of elderly patients with this disease develop end-stage kidney disease within 20 years ${ }^{12}$. IgA vasculitis in the elderly is complicated by renal insufficiency, especially in patients $\geq 60$ years old ${ }^{13)}$. Thus, it is important that we perform $\mathrm{KBx}$ to obtain a definite diagnosis of IgA nephropathy/vasculitis for proper patient management.

Nearly $100 \%$ of the patients with ANCA-associated glomerulonephritis and MCD received aggressive therapy. For these diagnoses, the interpretations of Table 7 could be different. Because ANCA-associated glomerulonephritis could be diagnosed only with a positive ANCA titer and signs of nephritis (such as active urinary sediment and elevated serum creatinine), if we knew in advance that nearly $100 \%$ of patients would receive aggressive therapy after the histologic diagnosis by $\mathrm{KBx}$, we could consider $\mathrm{KBx}$ not necessary for a diagnosis of ANCA-associated glomerulonephritis. In fact, since Nagao et al reported that anti-MPO antibody directly activated glomerular endothelial cells ${ }^{14)}$, it was highly possible that the patients with abnormal urinary findings had ANCAassociated glomerulonephritis if serum ANCA, particularly MPO-ANCA, was positive. In addition, histopathologic classification of ANCA-associated glomerulonephritis has been shown to predict survival differences, but KBX-based therapeutic strategies have not been explored ${ }^{15}$. Thus far, KBx has not influenced patient management. Recently, Endo et al reported that vasculitis of the small renal arteries was associated with systemic vasculitis, including pulmonary involvement ${ }^{16)}$, and ANCA-associated glomerulonephritis with renal thrombotic microangiopathy had a poor prognosis ${ }^{17}$. These findings suggest that $\mathrm{KBx}$ is important for the management of ANCA-associated glomerulonephritis.

In this study, MN and MCD were the leading final diagnoses. Yokoyama et al reported that the complete remission rate in elderly patients with MCD was similar to that of the non-elderly ${ }^{18}$. However, $\mathrm{MN}$, which increases with age, often achieves spontaneous remission. The mortality and end-stage kidney disease rates are significantly lower among patients with spontaneous remission ${ }^{19}$. Therefore, when de- 
termining proper management, it is important that we distinguish between MCD and MN by performing KBx.

Our study had several limitations. First, it was a single-center, retrospective, case-cohort study in which strategic bias may have existed. Second, our study did not adequately involve very elderly patients over 80 years of age. Moutzouris et al reported that this subset of patients should no longer be considered contraindicated for $\mathrm{KBx}^{20)}$. However, we suggest that $\mathrm{KBx}$ in the elderly is risky. From our study, we do not know whether $\mathrm{KBx}$ in patients over 80 years old is safe. Third, the sample size was small due to the single-center design. The event numbers are insufficient for a meaningful statistical analysis. Fourth, we did not determine the utility of KBx directly. We need to analyze the prognoses by comparing patients with and without $\mathrm{KBx}$ per diseases that we can diagnose serologically, such as ANCA-associated vasculitis.

\section{Conclusion}

$\mathrm{KBx}$ in the elderly could be considered as safe as that in the non-elderly if it is performed according to strict indications and with cautious discretion. $\mathrm{KBx}$ in this population is useful and important in terms of diagnosis and management.

\section{Conflict of interest}

None.

\section{Acknowledgment}

We thank Dr. Sayaka Shimizu of the Department of Healthcare Epidemiology, Kyoto University, for her help with the statistical analysis.

\section{References}

1) Imai E, Horio M, Yamagata K, et al. Slower decline of glomerular filtration rate in the Japanese general population: a longitudinal 10-year follow-up study. Hypertens Res 2008; 31: 433441.

2) Yamashita T, Yoshida T, Ogawa T, et al. Clinical outcomes in patients with chronic kidney disease: a 5-year retrospective cohort study at a University Hospital in Japan. Clin Exp Nephrol 2011; 15: 831-840.

3) Yokoyama H, Sugiyama H, Sato H, et al. Renal disease in the elderly and the very elderly Japanese. Clin Exp Nephrol 2012; 16: 903-920.

4) Schmitt R, Coca S, Kanbay M, et al. Recovery of kidney function after acute kidney injury in the elderly: a systematic review and meta-analysis. Am J Kidney Dis 2008; 52: 262-271.

5) Torres Muñoz A, Valdez-Ortiz R, GonzálezParra C, et al. Percutaneous renal biopsy of native kidneys: efficiency, safety and risk factors associated with major complications. Arch Med Sci 2011; 7: 823-831.

6) Eiro M, Katoh T, Watanabe T. Risk factors for bleeding complications in percutaneous renal biopsy. Clin Exp Nephrol 2005; 9: 40-45.

7) Levison SP. Renal disease in the elderly: the role of the renal biopsy. Am J Kidney Dis 1990 Oct; 16: 300-306.

8) Yang F, Li B, Cui W, et al. A clinicopathological study of renal biopsies from 288 elderly patients: analysis based on 4,185 cases. Int Urol Nephrol 2015; 47: 327-333.

9) Uezono S, Hara S, Sato $Y$, et al. Renal biopsy in elderly patients: a clinicopathological analysis Ren Fail 2006; 28: 549-555.

10) Korbet SM, Volpini KC, Whittier WL. Percutaneous renal biopsy of native kidneys: a singlecenter experience of 1,055 biopsies. Am J Nephrol 2014; 39: 153-162.

11) Seitz DP, Gill SS, Bell CM, et al. Postoperative medical complications associated with anesthesia in older adults with dementia. J Am Geriatr Soc 2014; 62: 2102-2109.

12) Oshima $Y$, Moriyama $T$, Itabashi $M$, et al. Characteristics of $\operatorname{IgA}$ nephropathy in advanced-age patients. Int Urol Nephrol 2015; 47: 137-145.

13) Pillebout E, Thervet E, Hill G, et al. HenochSchönlein Purpura in adults: outcome and prognostic factors. J Am Soc Nephrol 2002; 13: 1271-1278.

14) Nagao T, Matsumura M, Mabuchi A, et al. Upregulation of adhesion molecule expression in glomerular endothelial cells by anti-myeloperoxidase antibody. Nephrol Dial Transplant 2007; 22: 77-87.

15) Berden AE, Ferrario F, Hagen EC, et al. Histopathologic classification of ANCA-associated glomerulonephritis. J Am Soc Nephrol 2010; 21: $1628-1636$.

16) Endo A, Hoshino J, Suwabe T, et al. Significance of small renal artery lesions in patients with antineutrophil cytoplasmic antibody-associated glomerulonephritis. J Rheumatol 2014; 41: 1140-1146.

17) Chen SF, Wang H, Huang YM, et al. Clinic pathologic characteristics and outcomes of renal 
thrombotic microangiopathy in anti-neutrophil cytoplasmic autoantibody-associated glomerulonephritis Clin J Am Soc Nephrol 2015; 10: 750758.

18) Yokoyama H, Sugiyama H, Narita I, et al. Outcomes of primary nephrotic syndrome in elderly Japanese: retrospective analysis of the Japan Renal Biopsy Registry (J-RBR). Clin Exp Nephrol
2015; 19: 496-505.

19) Polanco N, Gutiérrez E, Covarsí A, et al. Spontaneous remission of nephrotic syndrome in idiopathic membranous nephropathy. J Am Soc Nephrol 2010; 21: 697-704.

20) Moutzouris DA, Herlitz L, Appel GB, et al. Renal biopsy in the very elderly. Clin J Am Soc Nephrol 2009; 4: 1073-1082. 